\title{
Pistacia atlantica Desf. A review of its traditional uses, phytochemicals and pharmacology
}

\author{
Fatemeh Mahjoub ${ }^{1}$, Kambiz Akhavan Rezayat ${ }^{2}$, Mahdi Yousefi ${ }^{3}$, Masoud Mohebbi ${ }^{4}$, Roshanak Salari ${ }^{5}$ \\ 1. MD, Ph.D candidate, Department of Persian medicine, School of Persian and complementary medicine, Mashhad University of Medical \\ Sciences, Mashhad, Iran \\ 2. Assistant Professor, MD, Department of Internal Medicine, School of Medicine, Mashhad University of Medical Sciences, Mashhad, Iran \\ 3. Assistant Professor, MD, Ph.D, Department of Persian Medicine, School of Persian and Complementary Medicine, Mashhad University of \\ Medical Sciences, Mashhad, Iran \\ 4. Assistant Professor, MD, Endocrine research center, Mashhad University of Medical Sciences, Mashhad, Iran \\ 5. Assistant Professor of Drug Control, Ph.D, Department of Pharmaceutical Sciences in Persian Medicine, School of Persian and comple- \\ mentary medicine, Mashhad University of Medical Sciences, Mashhad, Iran
}

Corresponding Author:
Prof. Roshanak Salari (Pharm.D, Ph.D)
Address: School of complementary and Persian medicine, Azadi square, Mashhad, Iran.
E-mail: salarir@mums.ac.ir
Tel: $+98-51-38829279$, Fax: $+98-51-38535980$

Received: November 13th, 2017 - Accepted: March 6th, 2018

\begin{abstract}
Pistacia atlantica is the main herbal medicine that has been widely used in the Middle Eastern and Mediterranean areas since ancient time. Pistacia atlantica has been used for multiple purposes like stomach diseases, renal disorders, wounds and coughs. The aim of this study is to review its botanical characterization, traditional applications, photochemistry effects and pharmacological activities. Data in this review article was gathered from credible pharmacopeias, electronic databases such as Web of Science, Science Direct, PubMed, EMBASE, Scopus, EBSCO, Google Scholar, SID and Iran Medex and textbooks of Persian medicine such as Canon of medicine (Ibn-e Sina, 980-1037 AD) and Makhzan-al-Advia (Aghili, 18th century). The keywords were searched in Persian and English books on medicinal plants and traditional medicine. The results showed that $P$. atlantica has many medicinal properties such as antioxidant, antidiabetic, antihyperlipidemic, along with others. It can also be effective in gastrointestinal diseases. Thus, different new drugs can be formulated based on $P$. atlantica for the management of various diseases.
\end{abstract}

Keywords: Pistacia atlantica; wild pistachio; traditional medicine; Persia

\section{Introduction}

The genus Pistacia (family of Anacardiaceae) includes over 600 species. P. vera, $P$. atlantica, $P$. terebinthus, $P$. khinjuk, and $P$. lentiscus are the most famous species of Pistacia that are widely distributed in the Mediterranean and Middle Eastern areas [1, 2]. More than $40 \%$ of the world production of Pistacia spp. is from Iran [3]. Iran's Pistacia cultivation history (3000-4000 years) represents different culinary and traditional medicinal applications for this herb. The most economical species of Pistacia genus is P. atlantica (wild pistachio), found in in Iran [4]. Besides Iran, wild pistachio grows in different countries like Pakistan, Greece, Turkey, and North Africa [5]. Cabulica, Kurdica, and Mutica are the three subspecies of P. atlantica [6]. Various industrial and traditional uses are mentioned for the main parts of wild pistachio (resin and fruit) including in foods and medicine. Recent research investigates the wide pharmacological properties from various parts of $P$. atlantica, such as antimicrobial, antioxidant, antidiabetic, antitumor, and antihyperlipidemic activities. In this review, traditional uses, phytochemistry and pharmacological activities of $P$. atlantica are described.

\section{Methods}

This Review has been written based on Persian and modern medical textbooks. Valid Persian medical references such as Al-Qanun Fi al-Tibb which is called Canon of medicine in Latin (Ibn-e Sina, 980-1037 AD), Makhzan-al-Advia (Aghili, 18th century) have been chosen. Science Direct, PubMed, Scopus, EBSCO, EMBASE, SID, IranMedex, and Google scholar databases were also searched by keywords Pistacia atlantica, wild pistachio, traditional medicine, and Persia, up until 2017.

\section{Results}

\section{Botany}

$P$. atlantica is a tree with a length of 2-5 m. The branches of the tree are grayish-white and have leaves composed of 9 
to 11 leaflets. Oleoresin is secreted by the trunk featuring a yellowish-green color and a mild smell. This plant is singlesex and has 5 sepals and no petals [7].

\section{Pistacia atlantica in traditional medicine}

In Persian, P. atlantica is called Baneh, in English Mt. Atlas mastic tree, in Arabic Butm, in the Canary Islands Almacigo, and in Turkish Melengic. The resin of wild pistachio called Saqez. Vanoshak is the name of tree fruits that has a green thin wrapper with a stiff shell and its marrow possesses nutritional value. Baneh have been mentioned as ripe fruits with delicious marrow $[7,8]$. Iran is one of the biggest producers and exporters of $P$. atlantica.

\section{Temperament of Pistacia atlantica in Persian medicine}

According to Persian medicinal literature, all the materials in the world exhibit four main qualities: "warmth", "coldness", "wetness", and "dryness" and Mizaj (temperament) is a predominant quality (or qualities). According to the previously-mentioned idea, herbal medicines have a specific temperament. Each particular part of the P. atlantica species has different degrees of temperament. Fresh fruit is warm and dry in degree 1 ; dried fruit is warm and dry in degree 3; resin is warm and dry in degree 2; fresh leaves and branches are warm and dry in degrees 2 and 1, respectively [9].

\section{Mode of application in traditional medicine}

Gastrointestinal effects

The fruit and resin of $P$. atlantica have beneficial effects in upper and lower gastrointestinal disorders. The resin is a stomach tonic and it is used for dyspepsia, stomach ulcer, esophagitis and gastritis. Oleoresin is an appetizer, a laxative, and it is advantageous for anal fissures. The fruit is carminative and effective in nausea and vomiting, colic, hemorrhoid, anal fissures and intestinal worms [9-12].

\section{Hepatic and splenic effects}

The fruit and resin of $P$. atlantica are liver tonics and have hepatoprotective properties. They are prescribed for hepatic weakness, hepatitis and ascites. The fruit is a spleen tonic and it is prescribed for splenic stagnation $[9,12]$.

\section{Neurological effects}

The resin and fruit of $P$. atlantica are nerve tonics and are useful in Bell's palsy, stroke, tetanus, seizure, tremor and headache $[9,12]$.

\section{Heart and psychological uses}

This plant has beneficial effects for palpitations and syncope; its fruit also has antidepressant properties [9].

\section{Respiratory benefits}

P. atlantica (resin \& fruit) are prescribed for pneumonia and productive cough due to mucolytic properties $[9,12]$.

\section{Urogenital effects}

The fruit of $P$. atlantica has been known as a kidney tonic and aphrodisiac; also, it is used for nephrolithiasis. This plant (resin \& fruit) has diuretic and emmenagogue properties $[9,12]$.

\section{Dermatologic benefits}

This plant is effective for wound healing, scabies, lip fissures and hair loss $[9,12,13]$.

\section{Miscellaneous}

The resin is a gum tissue strengthener and useful for bone fractures and musculoskeletal disorders. The fruit has been used for back pain due to its analgesic properties [9].

\section{Phytochemistry of Pistacia atlantica}

The chemical entities from different phytochemical groups were isolated and characterized in $P$. atlantica and mentioned in Table 1.

\section{Terpenoids}

An essential oil is one of the numerous metabolites extracted from the fruits, leaf-buds, twigs, flowers, leaves, resin, and galls of $P$. atlantica [8]. The main ingredients of the essential oils reported by hydrodistillation of the resin, leaves and fruits of P. atlantica based on GC (gas chromatography) and GC/MS (gas chromatography/mass spectrometry) is monoterpene with $\alpha$-pinene (42.9\%) and $\beta$-pinene (13.2\%) in the resin. Terpinen-4-ol (21.7\%) and elemol (20.0\%) are two major ingredients in the oil of the leaves. The oil of the fruits has high amounts of oxygenated monoterpenes, with bornyl acetate $(21.5 \%)$ as the predominant component [14]. Spathulenol is the main component of $P$. atlantica leaves [15]. Triterpenes like oleanolic acid, ursonic acid, masticadienonic acid, masticadienolic acid, morolic acid, and 3-0-acetyl-3-epiisomasticadienolic acid are detected in the resin of $P$. atlantica $[5,16]$.

\section{Phenolic Compounds}

Phenols are known for their antioxidant activities which reduce the risk of different diseases such as cancers [17]. Leaf extract contains two main chemical compounds of gallic acid and gallic acid methyl ester. Luteolin, luteolin 7-glycoside, chlorogenic acid, kampferol, naringin and naringin 7-glycoside were detected from the fruit extract [5]. Flavonoid glycosides were isolated from the aerial parts, leaves and stems of $P$. atlantica. These components 
Table 1: Chemical ingredients and their structure isolated from Pistacia atlantica Desf.

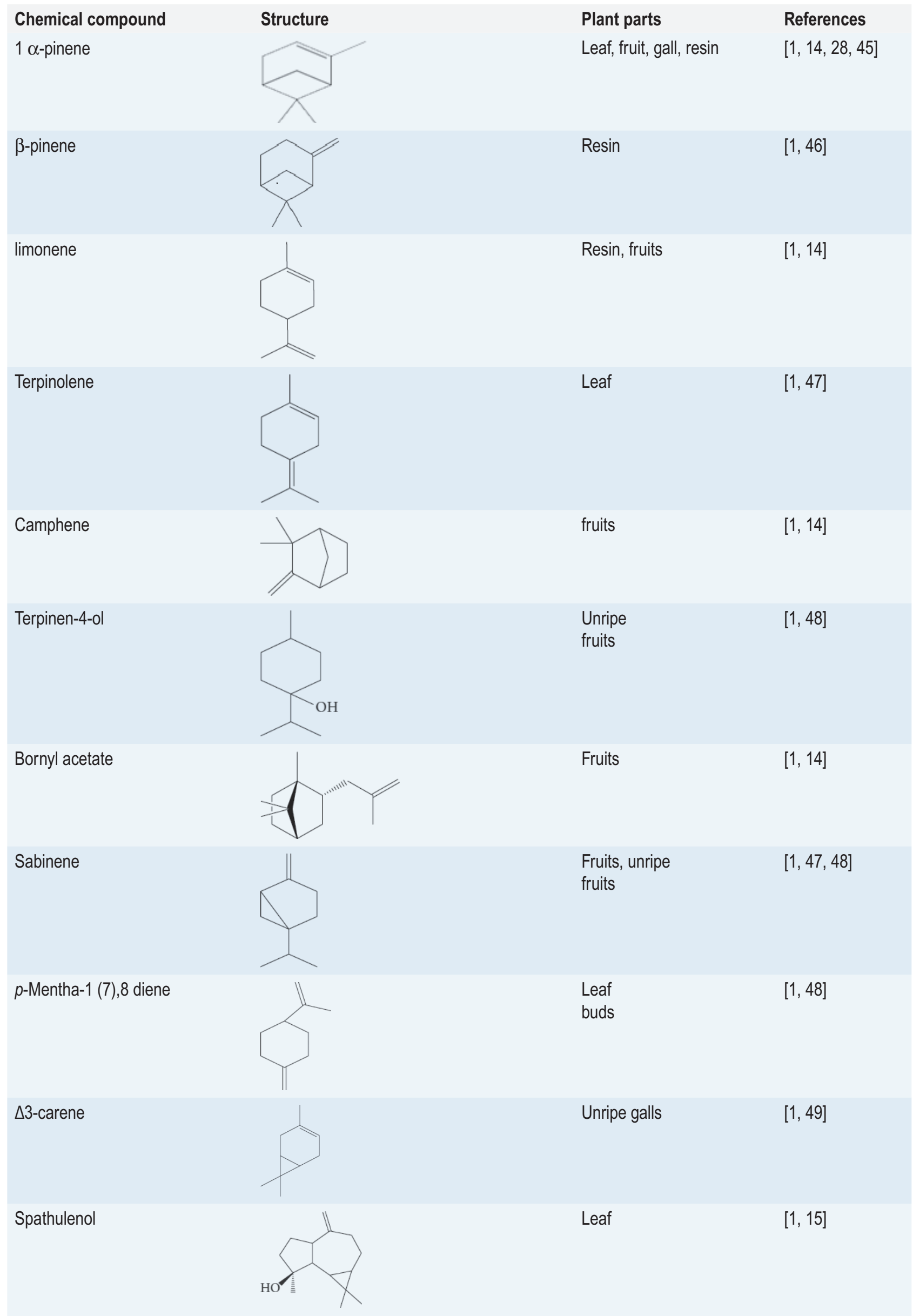


Table 1: Chemical ingredients and their structure isolated from Pistacia atlantica Desf.

\section{Chemical compound}

Masticadienonic acid

Masticadienolic acid

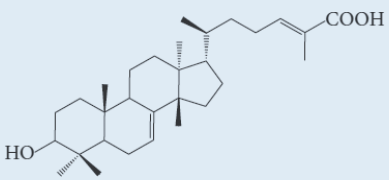

Morolic acid

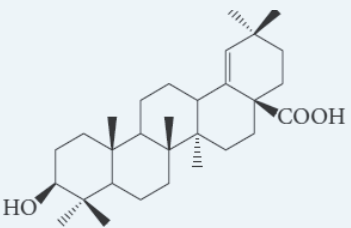

Oleanolic acid

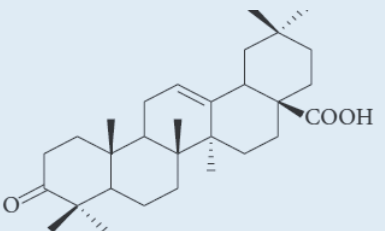

Ursonic acid

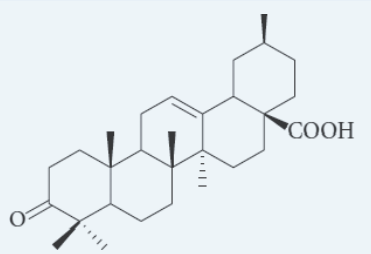

3-0-acetyl-3-epiisomasticadienolic acid

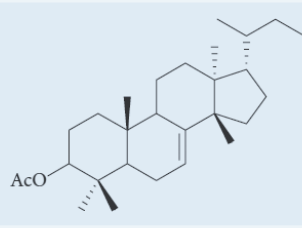

Gallic acid<smiles>O=C(O)c1cc(O)c(O)c(O)c1</smiles>

Quercetin-3-glucoside

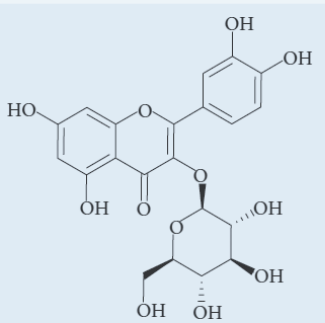

3-Methoxycarpachromene

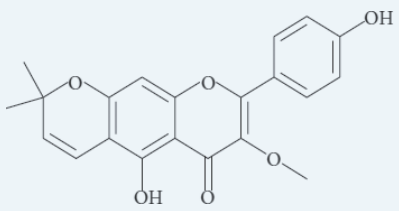

$\beta$-myrcene
Plant parts

Resin

References

$[1,16]$

$[1,16]$

Resin

$[1,16]$

$[1,16]$

$[1,16]$

Resin

$[1,16]$

Resin

$[1,5]$

Gall and Leaf

$[1,18]$

Aerial parts

$[1,19]$

Aerial parts

$[1,14]$ 
were revealed as kaempferol-3-glucoside, quercetin3-glucoside, quercetin-3-galactoside, quercetin-3rutinoside, quercetin-3-glucoside-7-galactoside, apigenin 6,8-di-C-glucoside (vicenin 2) [18]. Among flavonoids, 3-methoxycarpachromene has an antiplasmodial activity which is isolated from the aerial parts of P.atlantica [19].

\section{Fatty Acids and Sterols}

The fruits of P. atlantica are the main sources of unsaturated fatty acids. The ingredients of the oil content are oleic (46\%), linoleic $(27.5 \%)$, palmitic $(24 \%)$ and stearic acid $[10,20]$. The main sterol of the $P$. atlantica fruit oil is $\beta$-sitosterol $(87 \%)$, which is similar to peanuts and Pistacia vera [21]. Cholesterol, campesterol, $\Delta 5$-avenasterol, $\Delta 7$-avenasterol have been revealed from the sterol composition [10]. The sterol composition has an important role in preventing coronary heart diseases [22].

\section{Miscellaneous}

Tocopherols and tocotrienols are the other ingredients of $P$. atlantica hull oil with antioxidant properties [22, 23].

\section{Pharmacological effects}

\section{Antimicrobial Activities}

$P$. atlantica has antibacterial properties against a large number of Gram-positive and Gram-negative bacteria. The oleoresin from $P$. atlantica var. kurdica with its major component -pinene has antibacterial properties against Helicobacter pylori $[1,16]$. Another research showed that acidic fractions resin of $P$. atlantica has extensively inhibitory effects against Escherichia coli, Salmonella typhimurium, Pseudomonas aeruginosa, Alcaligenes faecalis, Enterobacter aerogenes, Pseudomonas fluorescens, Bacillus cereus, Streptococcus faecalis, Staphylococcus aureus and epidermidis [24-27]. The methanolic extract from $P$. atlantica fresh fruits has been shown to affect fungi and yeast, such as Candida albicans, Candida glabrata and Saccharomyces cerevisiae $[28,29]$. The leaves and twigs of $P$. atlantica with its active substance 3-methoxycarpachromene showed antiprotozoal activity against Plasmodium falciparum [19]. In addition, P. atlantica var. kurdica gum could prevent cutaneous leishmaniosis from infected mice [30].

\section{Antioxidant Activity}

The main phenolic compounds of the fruits and leaves of $P$. atlantica are benzoic acid derivates, hydroxycinnamic acid derivative, and flavonoids that have antioxidant properties. Sinapic acid, vanillic acid and p-hydroxybenzoic acid are metabolites of hull and shell extracts with antioxidant properties [31]. A study has demonstrated the existence of new natural antioxidant ingredients isolated from the mushroom Inonotus hispidus growing on $P$. atlantica including methyl 5-(3,4-dihydroxyphenyl)-3-hydroxypenta2,4-dienoate, hispolone 2 (6-(3,4-dihydroxyphenyl)4-hydroxyhexa-3,5-dien-2-one) and hispidin 3 (6-(2-(3,4-dihydroxyphenyl)vinyl)-4-hydroxy-2H-pyran-2one) $[29,32,33]$.

\section{Antihyperlipidemic effects}

Research on animals revealed that $P$. atlantica fruit oil decreased LDL cholesterol, VLDL cholesterol, triglycerides and increased HDL cholesterol. In one study, the lipid profiles were reduced in female rats with experimental hypothyroidism caused by propyl thiouracil (PTU) which received wild pistachio oil [34, 35].

\section{Hypoglycemic effects}

Aqueous leaf extract from $P$. atlantica has hypoglycemic effects due to the inhibitory effect on $\alpha$-amylase and $\alpha$-glucosidase $[36,37]$. An in vivo study has also shown postprandial glucose improvement equal to glipizide and metformin and higher than acarbose in rats [37].

\section{Anticancer activity}

The cytotoxic effects of fruit methanolic extract from $P$. atlantica sub. kurdica were approved against two human cancer cell lines including the human colon carcinoma (HT29), and the human breast cancer (T47D). P. atlantica extract can alternate tubular protein organization with inhibitory effects on microtubule polymerization and dynamics [38-40].

\section{Anticholinesterase Activity}

Aqueous extracts of $P$. atlantica leaves demonstrated strong acetylcholinesterase (AChE) inhibition [41], whereas both methanol and ethyl acetate extracts of $P$. atlantica leaf exhibited relatively weak AChE inhibitory activity [42].

\section{Wound-healing effects}

Tanideh et al. demonstrated that the resin extract is effective in burn wounds by increasing angiogenesis, concentration of basic fibroblast growth factor (bFGF) and platelet-derived growth factor (PDGF) [43]. The results of another clinical trial showed that oleoresin of $P$. atlantica has a beneficial effect on nipple fissures and pain [44].

\section{Gastrointestinal benefits}

$P$. atlantica has anti-inflammatory activity and an appropriate effect in the treatment of ulcerative colitis. One study on animals exhibited that fruit oil can improve colitis in rats [43]. 


\section{Discussion}

According to the Persian medical literature and recent studies, $P$. atlantica has various applications for dietetic and medicinal purposes. This review investigated extensive evidence on phytochemical and pharmacological features. Some of the therapeutic uses in traditional medicine are supported by recent studies, such as their beneficial effects on gastrointestinal disorders, but there are several pharmacological activities discussed in traditional medicine such as aphrodisiac activities, diuretic, emmenagogue, which are not confirmed by any current scientific documents, and therefore, further studies should be performed.

\section{Acknowledgments}

This article is based on the secondary results of $\mathrm{Dr}$. Fatemeh Mahjoub's PhD postgraduate thesis.

This study was supported by the Mashhad University of Medical Sciences Research Council, Mashhad, Iran (Grant no. 950153).

\section{Conflict of Interest}

The authors confirm that there are no conflicts of interest.

\section{References}

1. Bozorgi M, Memariani Z, Mobli M, Salehi Surmaghi MH, ShamsArdekani MR, Rahimi R. Five Pistacia species (P. vera, $P$. atlantica, $P$. terebinthus, $P$. khinjuk, and $P$. lentiscus): a review of their traditional uses, phytochemistry, and pharmacology. The Scientific World Journal. 2013; doi.org/10.1155/2013/219815

2. Mozaffarian V. Trees and Shrubs of Iran. 1st edition ed. Tehran: Farhang Moaser; 2005.

3. Daneshpour F. Optimizing the pistachio supply chain and logistics network for Fresno county using geographic information systems network analysis method: California Polytechnic State University, San Luis Obispo; 2015.

4. Razavi S, editor Pistachio production, Iran vs. the world. IV International Symposium on Pistachios and Almonds 726; 2005.

5. Duhem B, Gaydou EM. Isolation and characterization of a new hispolone derivative from antioxidant extracts of Pistacia atlantica. Phytother Res. 2009; doi: 10.1002/ptr.2543

6. Pourreza M, Shaw JD, Zangeneh $\mathrm{H}$. Sustainability of wild pistachio (Pistacia atlantica Desf.) in Zagros forests, Iran. Forest Ecology and Management. 2008; doi.org/10.1016/j.foreco.2008.01.057

7. Mozaffarian V. A Dictionary of Iranian Plant Names, Farhang Moaser Iran: Tehran; 1998.

8. Bahmani M, Saki K, Asadbeygi M, Adineh A, Saberianpour S, Rafieian-Kopaei M, Bahmani F, Bahmani $E$. The effects of nutritional and medicinal mastic herb (Pistacia atlantica). J Chem Pharm Res. 2015; http://eprints.skums.ac.ir/id/eprint/2025
9. Aghili MH. Makhzan-al-Advie (Persian). Tehran: Tehran University of Medical Sciences; 2009.

10. Yousfi M, Nedjmi B, Bellal R, Ben Bertal D, Palla G.Fatty acids and sterols of Pistacia atlantica fruit oil. Journal of the American Oil Chemists' Society. 2002; https://doi.org/10.1007/s11746-0020601-8

11. MosaddeghM,NaghibiF,MoazzeniH,PiraniA, EsmaeiliS. Ethnobotanical survey of herbal remedies traditionally used in Kohghiluyeh va Boyer Ahmad province of Iran. Journal of ethnopharmacology. 2012; PMID: 22366675, DOI: 10.1016/j.jep.2012.02.004

12. Avicenna. Al-Qanun fi al-Tibb (The Canon of Medicine). Beirut: Alamy Le- Al-Matbooat institute; 2012.

13. Yousfi M, Nadjemi B, Belal R, Bombarda I, Gaydou E. Triacylglycerol composition of oil from Pistacia atlantica fruit growing in Algeria. Journal of the American Oil Chemists' Society. 2005; https://doi. org/10.1007/s11746-005-1048-7

14. Barrero A, Herrador M, Arteaga J, Akssira M, Mellouki F, Belgarrabe A, Blázquez MA. Chemical composition of the essential oils of Pistacia atlantica Desf. Journal of Essential Oil Research. 2005; http://dx.doi.org/10.1080/10412905.2005.9698828

15. Said SA, Fernandez C, Greff S, Derridj A, Gauquelin T, Mevy J-P. Inter-population variability of leaf morpho-anatomical and terpenoid patterns of Pistacia atlantica Desf. ssp. atlantica growing along an aridity gradient in Algeria. Flora-Morphology, Distribution, Functional Ecology of Plants. 2011; https://doi. org/10.1016/j.flora.2010.08.002

16. Sharifi MS, Hazell SL. Isolation, analysis and antimicrobial activity of the acidic fractions of Mastic, Kurdica, Mutica and Cabolica gums from genus Pistacia. Global journal of health science. 2012; PMCID: PMC4777032

17. Ferreira IC, Barros L, Soares ME, Bastos ML, Pereira JA. Antioxidant activity and phenolic contents of Olea europaea $\mathrm{L}$. leaves sprayed with different copper formulations. Food Chemistry. 2007; https://doi.org/10.1016/j.foodchem.2006.08.006

18. Kawashty S, Mosharrafa S, El-Gibali M, Saleh N. The flavonoids of four Pistacia species in Egypt. Biochemical Systematics and Ecology. 2000;28(9):915-7.

19. Adams M, Plitzko I, Kaiser M, Brun R, Hamburger M. HPLC-profiling for antiplasmodial compounds-3-Methoxycarpachromene from Pistacia atlantica. Phytochemistry Letters. 2009; https://doi. org/10.1016/j.phytol.2009.05.006

20. Benhassaini $H$, Bendahmane $M$, Benchalgo $N$. The chemical composition of fruits of Pistacia atlantica desf. subsp. atlantica from Algeria. Chemistry of Natural Compounds. 2007; https://doi. org/10.1007/s10600-007-0059-4

21. Yıldız M, Gürcan ŞT, Özdemir M. Oil composition of pistachio nuts(Pistacia vera L.) from Turkey. Lipid- Fett. 1998;100(3):84-6.

22. Givianrad M, Saber-Tehrani M, Mohammadi SJ. Chemical composition of oils from wild almond (Prunus scoparia) and wild pistachio (Pistacia atlantica). Grasas y aceites. 2013; http://dx.doi. org/10.3989/gya.070312

23. Foster R, Williamson C, Lunn J. BRIEFING PAPER: Culinary oils and their health effects. Nutrition Bulletin. 2009; DOI: 10.1111/j.1467-3010.2008.01738.x

24. Tohidi M, Khayami M, Nejati V, Meftahizade $H$. Evaluation of antibacterial activity and wound healing of Pistacia atlantica and Pistacia khinjuk. Journal of Medicinal Plants Research. 2011;5(17):4310-4.

25. Yoram G, Inbar M. Distinct antimicrobial activities in aphid galls on Pistacia atlantica. Plant signaling \& behavior. 2011; http://dx.doi. org/10.4161/psb.6.12.18031

26. Delazar A, Nazemieh H, Modaresi M, Afshar J. Study on essential oil obtained from oleoresin of Pistacia atlantica var. mutica. 2003. 
27. Ghalem B, Benali M. Bactericidal activity of Pistacia atlantica. Desf mastic gum against certain pathogens. African Journal of Plant Science. 2009;3(1):013-5.

28. Falahati $M$, Sepahvand $A$, Mahmoudvand $H$, Baharvand $P$, Jabbarnia S, Ghojoghi A, Yarahmadi M. Evaluation of the antifungal activities of various extracts from Pistacia atlantica Desf. Current Medical Mycology. 2015; DOI: 10.18869/acadpub.cmm.1.3.25

29. Benhammou N, Bekkara FA, Panovska TK. Antioxidant and antimicrobial activities of the Pistacia lentiscus and Pistacia atlantica extracts. African Journal of Pharmacy and Pharmacology. 2008;2(2):022-8.

30. Taran M, Mohebali M, Esmaeli J. In vivo efficacy of gum obtained Pistacia atlantica in experimental treatment of cutaneous leishmaniasis. Iranian journal of public health. 2010; PMID: 23112988,PMCID: PMC3468973

31. Hatamnia AA, Abbaspour N, Darvishzadeh R. Antioxidant activity and phenolic profile of different parts of Bene (Pistacia atlantica subsp. kurdica) fruits. Food chemistry. 2014; PMID: 24128482, DOI: 10.1016/j.foodchem.2013.08.031

32. Rezaie M, Farhoosh R, Iranshahi M, Sharif A, Golmohamadzadeh S. Ultrasonic-assisted extraction of antioxidative compounds from Bene (Pistacia atlantica subsp. mutica) hull using various solvents of different physicochemical properties. Food chemistry. 2014; PMID: 25466062, DOI: 10.1016/j.foodchem.2014.10.081

33. Sharif A, Farhoosh R, Khodaparast MHH, Kafrani MHT. Antioxidant activity of bene hull oil compared with sesame and rice bran oils during the frying process of sunflower oil. Journal of Food Lipids. 2009; DOI: 10.1111/j.1745-4522.2009.01154.x.

34. Saeb M, Nazifi S, Mirzaei A. The effects of willd pistacio fruit oil on the serum concentration of lipids and Lipoproteins of female rabbits. Journal of Shahid Sadoughi University of Medical Sciences And Health Services. 2004; URL: http://jssu.ssu.ac.ir/ article-1-1248-en.html

35. Nazifi S, Saeb M, Sepehrimanesh M, Poorgonabadi S. The effects of wild pistachio oil on serum leptin, thyroid hormones, and lipid profile in female rats with experimental hypothyroidism. Comparative Clinical Pathology. 2012;21(5):851-7.

36. Hamdan I, Afifi F. Studies on the in vitro and in vivo hypoglycemic activities of some medicinal plants used in treatment of diabetes in Jordanian traditional medicine. Journal of ethnopharmacology. 2004; PMID: 15182916, DOI: 10.1016/j.jep.2004.03.033

37. Kasabri V, Afifi FU, Hamdan I. In vitro and in vivo acute antihyperglycemic effects of five selected indigenous plants from Jordan used in traditional medicine. Journal of ethnopharmacology. 2011; https://doi.org/10.1016/j.jep.2010.11.025

38. Rezaei PF, Fouladdel S, Hassani S, Yousefbeyk F, Ghaffari SM, Amin G, Azizi E. Induction of apoptosis and cell cycle arrest by pericarp polyphenol-rich extract of Baneh in human colon carcinoma HT29 cells. Food and Chemical Toxicology. 2012; https://doi.org/10.1016/j.fct.2011.11.012

39. Shafiei B, Shasaltaneh MD, Ghaffari S, Ahmadian S, Kamarehei M, Raizi G. An in vitro study on the effect of Pistacia atlantica sub Kurdica extract on microtubule proteins a potential anti-cancer compound. International Journal of Pharmaceutical Sciences and Research. 2015;6(12):5029.

40. Rezaei PF, Fouladdel S, Ghaffari SM, Amin G, Azizi E. Induction of $\mathrm{G} 1$ cell cycle arrest and cyclin D1 down-regulation in response to pericarp extract of Baneh in human breast cancer T47D cells. DARU Journal of Pharmaceutical Sciences. 2012; https://doi. org/10.1186/2008-2231-20-101

41. Benamar H, Rached W, Derdour A, Marouf A. Screening of Algerian medicinal plants for acetylcholinesterase inhibitory activity. Journal of Biological Sciences. 2010; http://scialert.net/qredirect. php?doi.

42. Peksel A, Arisan-Atac I, Yanardag R. Evaluation of antioxidant and antiacetylcholinesterase activities of the extracts of Pistacia atlantica Desf. Leaves. Journal of food biochemistry. 2010; DOI: 10.1111/j.1745-4514.2009.00290.x

43. Tanideh N, Masoumi S, Hosseinzadeh M, Safarpour AR, Erjaee $\mathrm{H}$, Koohi-Hosseinabadi O, Rahimikazerooni S. Healing effect of pistacia atlantica fruit oil extract in acetic Acid-induced colitis in rats. Iranian journal of medical sciences. 2014; PMCID: PMC4242986

44. As'adi N, Kariman N, Mojab F, Pourhoseingholi MA. The effect of Saqez (Pistacia atlantica) ointment on the treatment of nipple fissure and nipple pain in breastfeeding women. Electronic physician. 2017; DOI: http://dx.doi.org/10.19082/4952

45. Mecherara-Idjeri S, Hassani A, Castola V, Casanova J. Composition of leaf, fruit and gall essential oils of Algerian Pistacia atlantica Desf. Journal of Essential Oil Research. 2008; http://dx.doi.org/10. 1080/10412905.2008.9699995

46. Delazar A, Reid R, Sarker S. GC-MS analysis of the essential oil from the oleoresin of Pistacia atlantica var. mutica. Chemistry of Natural Compounds. 2004; https://doi.org/10.1023/ B:CONC. $0000025459.72590 .9 \mathrm{e}$

47. Roitman JN, Merrill GB, Beck JJ. Survey of ex situ fruit and leaf volatiles from several Pistacia cultivars grown in California. Journal of the Science of Food and Agriculture. 2011; PMID: 21384363, DOI: 10.1002/jsfa.4268

48. Tzakou O, Bazos I, Yannitsaros A. Volatile metabolites of Pistacia atlantica Desf. from Greece. Flavour and fragrance journal. 2007; DOI: $10.1002 / f f j .1805$

49. Gourine N, Yousfi M, Bombarda I, Nadjemi B, Stocker P, Gaydou E. Antioxidant activities and chemical composition of essential oil of Pistacia atlantica from Algeria. Industrial Crops and Products. 2010; https://doi.org/10.1016/j.indcrop.2009.10.003 